\title{
EL DERECHO HUMANO A LA IGUALDAD EN LA CONSTITUCIÓN MEXICANA, ALGUNAS CONSIDERACIONES
}

\author{
The human right to equality in the mexican \\ Constitution: some considerations
}

\author{
Sergio Arnoldo MORÁN NAVARRO' \\ Ma. Antonia ABUNDIS ROSALES
}

\begin{abstract}
Sumario
I. Introducción; II. Algunos aspectos de la evolución histórica de la igualdad; III. Principios, normas, reglas y garantías; IV. El principio de igualdad en la Constitución Política de los Estados Unidos Mexicanos; V. La igualdad formal. VI. La igualdad ante la ley y sus manifestaciones: a) La igualdad en la ley; b) La igualdad en la aplicación de la ley; c) La igualdad en el contenido de la ley; e) La prohibición de discriminar; VII. La igualdad sustantiva o material y sus manifestaciones: a) La igualdad de oportunidades b) La igualdad en los resultados c) La igualdad de trato VIII. Conclusiones.
\end{abstract}

Resumen: Este trabajo es un análisis de la igualdad, mismo que se inicia con un breve panorama de su evolución. El estudio de la igualdad parte de tres concepualizaciones: como principio, como norma y como garantía. Asimismo, se reflexiona sobre el principio de igualdad desde la Constitución, para después hacer referencia a las dos clases de igualdad: formal y sustancial o material, así como a sus respectivas manifestaciones, en las que se hace visible el avance que ha supuesto en las decisiones de la Suprema Corte de Justicia.

Palabras clave: Derechos Humanos. Igualdad. Principio. Igualdad formal. Igualdad real.

Abstract: This paper is an analysis of equality, same that begins with a brief overview of its evolution. The study parts from three conceptualizations: as a principle, as a rule and as a guarantee. It also reflects on the principle of equality from the Constitution, then refer to the two kinds of equality: formal, substantial or material, as well as their respective manifestations, which becomes visible the significant progress made in the decisions of the Supreme Court.

Key words: Humans Rights. Equality. Principle. Formal equality. Real Equality.

\footnotetext{
${ }^{1}$ Doctor en Derecho por la Universidad Complutense de Madrid, España, Profesor Titular en la Universidad Autónoma de Nayarit e integrante del Sistema Nacional de Investigadores, Nivel I.

${ }^{2}$ Doctora en Derecho por la Instituto de Altos Estudios Jurídicos de Jalisco, Profesora del Centro Universitario de la Costa, Campus Puerto Vallarta, de la Universidad de Guadalajara.
} 


\section{INTRODUCCIÓN}

La importancia que en la actualidad tiene la igualdad como principio fundamental de los derechos humanos que garantiza el reconocimiento de prerrogativas inherentes a todas las personas, por su indiscutible condición humana, origina el interés de analizar este principio y sus diversas manifestaciones, sin dejar de considerar de manera breve, algunos aspectos de su evolución histórica. Para emprender el análisis del principio de igualdad se estimó oportuno hacer referencia a la distinción entre principios, normas y reglas, que permita determinar la relevancia de la igualdad como principio.

El principio de igualdad se contiene en diversos artículos la Constitución de distintos maneras, principalmente en el primer párrafo del artículo $1^{\circ}$ se reconoce a todas las personas la igualdad en la titularidad de los derechos humanos reconocidos tanto en dicha constitución como en los tratados internacionales, así como las garantías de protección de tales derechos y, además, en el párrafo tercero se incluye la prohibición de discriminar.

La concepción de la igualdad como garantía genérica del orden normativo nacional e internacional, es esencial para la salvaguardia de los derechos humanos y, se traduce en una amplia obligación para el Estado para asegurar el libre y pleno ejercicio de los derechos humanos, por lo tanto, se incluye el estudio de este principio en sus dimensiones formal y material, así como sus manifestaciones específicas.

La finalidad de este estudio es analizar los diferentes enfoques desde los que la igualdad puede analizarse así como el desarrollo que la igualdad ha tenido hasta convertirse en el eje fundamental en el reconocimiento de los derechos humanos, además de lograr trascender en las decisiones de la Suprema Corte de Justicia de Nación.

\section{ALGUNOS ASPECTOS DE LA EVOLUCIÓN HISTÓRICA DE LA IGUALDAD}

El principio de igualdad ha tenido una esencial importancia, misma que en la actualidad se ha fortalecido. A través de la evolución histórica que el principio de igualdad ha tenido, la concepción de este se ha transformado y se han ido incorporando sus diferentes dimensiones.

En el estado liberal de derecho la igualdad se entendía como el respeto a la vida y la aplicación del orden jurídico a todos sin excepción y sin diferencia alguna. Las primeras reivindicaciones de la igualdad se ubican en la Revolución Francesa y, se manifiesta en la Declaración de Derechos del Hombre y del Ciudadano de 1787, específicamente en el artículo $1^{\circ}$ los hombres nacen y permanecen libres e iguales en derechos. Las distinciones sociales sólo pueden fundarse en la utilidad común. La declaración de Derechos del Buen pueblo de Virginia de 1776 contiene declaraciones semejantes.

La igualdad en esta etapa se enunció en torno al concepto de igualdad formal concebida como igualdad formal la que se manifiesta como igualdad jurídica y como generalidad de la ley. Sin embargo, esta concepción de igualdad ante la ley fue insuficiente; con la pura igualdad formal las desigualdades no disminuyeron, por lo que se hizo necesario que a la igualdad ante la ley se integrara la igualdad en la ley o en el contenido de la ley.

En el estado social el principio de igualdad se convierte en un instrumento de transformación social. Es el Estado constitucional posterior a la Segunda Guerra Mundial, el que finalmente incorpora el principio de igualdad como igualdad material, que desde entonces 
convive con el principio de igualdad formal y sus manifestaciones: igualdad ante la ley e igualdad en la ley.

Así, la idea de igualdad es uno de los parámetros fundamentales del pensamiento y de la organización social, económica, política y jurídica de las sociedades democráticas de nuestro tiempo. ${ }^{3}$

\section{PRINCIPIOS, NORMAS, REGLAS Y GARANTÍAS}

Previo al estudio del principio de igualdad en la Constitución mexicana y sus diferentes manifestaciones, es oportuno determinar cuál es la naturaleza de los principios jurídicos así como los rasgos que los caracterizan.

Partiendo de la afirmación de que los principios indican las conductas consideradas valiosas y, como tales deben ser realizadas; si los principios orientan respecto de las conductas que deben observarse, entonces componen una clase de normas, las que establecen prohibiciones o prescriben acciones.

De manera genérica una norma puede definirse como el conjunto de principios o reglas de conducta dirigidas a regular la vida de las personas en sociedad. Los ordenamientos jurídicos se componen de normas. Las normas son orientaciones dirigidas a inducir un determinado comportamiento en aquellos a los que van destinadas.

Las normas pueden clasificarse en dos grandes conjuntos: los principios y las reglas. Los principios son normas de carácter muy general, y pueden considerarse principios en sentido estricto o directrices. Los principios en sentido estricto expresan los valores superiores de un ordenamiento jurídico; las directrices son normas que establecen la exigencia de lograr ciertos fines. Las reglas son modelos de comportamiento que pueden ser específicas.

De acuerdo con Alexy, los principios y las reglas son normas porque unos y otros dicen lo que debe ser y, establece como criterios de distinción entre ambos, el alto grado de generalidad de los principios y el nivel de generalidad relativamente bajo de las reglas; ${ }^{4}$ de manera que de acuerdo al criterio de generalidad, la primera puede clasificarse como principio y la segunda como regla.

Sin embargo, Alexy reflexiona acerca de la diferencia entre reglas y principios y deduce que tal distinción es cualitativa y no de grado, pues los principios son normas que ordenan que algo sea realizado en la mayor medida posible dentro de las posibilidades jurídicas y reales existentes. ${ }^{5}$ Por lo que considera a los principios como mandatos de optimización, que se caracterizan porque pueden ser cumplidos en diferente grado y la medida de su cumpli-

\footnotetext{
3 CERDÁ MARTÍNEZ-Pujalte, Carmen, "Los principios constitucionales de igualdad de trato y de prohibición de la discriminación: Un intento de delimitación", Cuadernos constitucionales de la Cátedra Fadrique Furió Ceriol, España, núm. 50-51, 2005, p. 193. http://dialnet.unirioja.es/servlet/articulo?codigo=2538666 (consultado el 11 de julio de 2014)

4 Alexy, Robert, Teoría de los derechos fundamentales, Madrid, Centro de Estudios Constitucionales, 1993, pp. 83-84, http://www.iedf.org.mx/sites/DDHH/publicaciones/o1.pdf

5 Ibidem, p. 86.
} 
miento depende de las posibilidades reales y jurídicas y el ámbito de éstas lo determinan los principios y reglas opuestos.

Por el contrario, las reglas son normas que sólo pueden ser cumplidas o no. Debe acatarse lo que una regla exige siempre que sea válida. Contienen determinaciones en el ámbito de lo fáctico y jurídicamente posible. ${ }^{6}$ Así, concluye que toda norma es una regla o un principio.

Desde nuestro punto de vista, las cualidades que los principios poseen permiten diferenciarlos del resto de las demás normas. Los principios son fundamentales: determinan la justificación de una acción; explican el por qué debe una conducta realizarse o evitarse; son generales: ordenan de manera genérica, señalan los límites entre lo que es admisible y lo que no lo es; límites que no deben ser traspasados.

Los principios definen las conductas que son válidas y auxilian a que se entiendan cuáles son los criterios que deben guiar las conductas. Los principios son normas abiertas porque carecen de determinación fáctica, es decir, no tienen un catálogo exhaustivo de los supuestos en que procede o queda excluida su aplicación, por lo que requieren de un juicio de razonabilidad a favor de una u otra de las opciones que se presentan como alternativa, por lo tanto, no determinan necesariamente la decisión.

Los principios poseen una dimensión de importancia, misma que se aprecia cuando al colisionar dos principios, necesariamente a uno de ellos se le concede mayor peso sin que se invalide al otro que, seguirá aplicándose pero en menor grado. El análisis inició a partir de la idea de que los principios integran una clase normas. Esta postura encuentra su antítesis en la posición que afirma que los principios no pueden ser considerados como normas sino como el fundamento de éstas. De acuerdo a este enfoque, el principio constituye la base, el criterio o la justificación del mandato susceptible de aplicación. La norma es la concreción del principio.

En párrafos anteriores se dijo que los principios en sentido estricto expresan los valores superiores de un ordenamiento jurídico y requieren de un juicio de razonabilidad para determinar la relevancia del valor. La formulación de ese juicio de razonabilidad respecto del valor considerado como relevante, es lo que concreta el principio jurídico.

Los principios jurídicos cumplen una función informadora para todo el ordenamiento jurídico, esto es, determinan el contenido de la Constitución y de las leyes que de ella emanan, lo que les confiere eficacia y efectividad en la tarea de interpretación y aplicación del Derecho. Al estar contenidos en la Constitución comparten su fuerza normativa respecto de las demás normas del ordenamiento, adquiriendo el carácter de lineamientos constitucionales que sirven como fundamento a la creación de nuevas normas o bien, a la modificación de las ya existentes.

Regresando a la afirmación de Alexy de que toda norma es una regla o un principio, se hace necesario precisar si los conceptos de norma y principio son intercambiables.

Haciendo referencia a la igualdad, si puede comprobarse efectivamente que las personas son diferentes entre sí debido a múltiples factores como el género, la edad o las capacidades, entonces, siguiendo a Alexy, puede afirmarse que la igualdad es una norma, dado que las normas se caracterizan por contener determinaciones en el ámbito de lo fáctico y jurídicamente posible.

La igualdad puede plantearse como garantía genérica del orden normativo, es decir, como norma. Al respecto, Juventino Castro afirma que:

\footnotetext{
${ }^{6}$ Ibídem, p 86-87. 
La igualdad no se enuncia respecto de los hombres, sino de las leyes al regular los derechos e interrelaciones de aquellos, y de los tribunales al interpretar y aplicar dichas leyes. Esto último es una garantía de un orden jurídico, que permite que éste aproveche a todos los individuos por igual, independientemente de la desigualdad que está implícita en la fenomenología de las personas, porque de otra forma el orden jurídico no sería justo al permitir privilegios o excepciones a ciertas personas, que no se reconoce a otras en idénticas circunstancias. ${ }^{7}$

Si los principios definen los criterios que deben guiar las conductas en determinadas condiciones y además, informan a todo el ordenamiento jurídico en cuanto a la titularidad de los derechos fundamentales, entonces la igualdad es igualmente un principio que al reconocer la igualdad de toda persona ante la ley, los que en iguales circunstancias deben ser tratados igualmente sin privilegio ni favor alguno, revela el carácter abierto del principio. Asimismo, el principio de igualdad manifiesta un carácter relativo, dado que no puede pretenderse un trato igual cuando las circunstancias son desiguales.

Por otra parte, la igualdad puede percibirse como una garantía desde el punto de vista de su finalidad: proteger los derechos fundamentales de las personas contra cualquier abuso o arbitrariedad, sea que provenga de la autoridad pública o de particulares.

Un principio es el fundamento de una garantía, por lo tanto ésta, no es un principio. Los principios al estar plasmados en la constitución, adquieren el carácter de garantías. Así, el reconocimiento de la igualdad contenida en el artículo $1^{\circ}$ de la Constitución Política de los Estados Unidos Mexicanos, se traduce en protección jurídica para todas las personas, y proteger, es la finalidad de una garantía.

IV. EL PRINCIPIO DE IGUALDAD EN LA CONSTITUCIÓN POLÍtiCA DE LOS ESTAdOS UNidos MEXICANOS

El principio de igualdad como ha sido entendido por el derecho constitucional, concibe que todas las personas deban ser tratadas igualitariamente por el Estado respecto a lo que es esencialmente igual en todos ellos, es decir, en los derechos fundamentales reconocidos en la Constitución. Soberanes Díez, identifica a la igualdad como un principio, debido a que se expresa como un mandato de optimización, tiene estructura de concepto y proyección normativa. ${ }^{8}$

La igualdad como principio tiene su fuente diversos artículos de la Constitución Política de los Estados Unidos Mexicanos, específicamente en el artículo $1^{\circ}$ que en su primer párrafo reconoce a todas las personas la igualdad en la titularidad de los derechos humanos reconocidos tanto en dicha constitución como en los tratados internacionales, así como las garantías de protección de tales derechos y, en el párrafo tercero se incluye el mandamiento de no discriminación.

La Constitución, que es la norma suprema, prevé la igualdad de todas las personas, por lo tanto, su valor y eficacia prevalece frente a cualquier otra norma. La igualdad al surgir como principio de la Constitución, se proyecta en el conjunto de las leyes secundarias las que, de acuerdo con el principio de supremacía de la Constitución, éstas no pueden contradecir a la

7 CASTRO, Juventino V., Garantías y Amparo, 14 a ed., México, Porrúa, 2004, p. 192.

8 SOBERANES DÍEZ, José María, La igualdad y la desigualdad jurídicas, México, Porrúa, 2011, pp. 35-36. 
norma constitucional, lo que pone de manifiesto el significado exacto de la igualdad como principio.

Así, el principio de igualdad se establece como uno de los valores superiores del orden jurídico, ha de usarse como criterio básico para la producción normativa y su posterior interpretación y aplicación, asimismo, consagrado como principio y derecho, constituye un límite a la actuación de los órganos del Estado y es un derecho fundamental.

El poder legislativo se encuentra vinculado al principio de igualdad a través del artículo $1^{\circ}$ que establece el mandato de no discriminación y del artículo $4^{\circ}$ que dispone la igualdad entre el hombre y la mujer, ambos de la Constitución. El principio de igualdad como límite a la actividad del Poder Legislativo, exige razonabilidad en la diferencia de trato, como criterio básico para la producción normativa. De acuerdo con los criterios de la Suprema Corte de Justicia de la Nación, el legislador se encuentra vinculado al principio de igualdad a través del mandato de trato igual en supuestos y hechos equivalentes, excepto ante un fundamento objetivo y razonable que permita un trato desigual; asimismo, el mandato para el legislador de tratamiento desigual, que lo obliga a establecer diferencias entre supuestos de hecho distintos siempre que la Constitución las imponga.

El poder judicial se haya vinculado al principio de igualdad a través de la obligación de la creación de la jurisprudencia señalada en el artículo $94^{\circ}$ y que se concreta en los artículos 192 y 193 de la Ley de Amparo. El principio de igualdad como límite al poder judicial se esboza como obligación de respetar el principio de igualdad, como deber de imparcialidad para los jueces; como prohibición de incurrir en formas de trato desigual y como obligación para el operador del derecho de analizar si un tratamiento diferenciado constituye o no un acto o ley discriminatoria, por lo que la razonabilidad como principio aplicado al derecho, funge como herramienta interpretativa, integradora, limitativa, fundamentadora y sistematizadora del orden jurídico. ${ }^{9}$ En ese, sentido, un completo control de razonabilidad debe incluir el examen acerca de la afectación a los derechos fundamentales y su contenido esencial.

De acuerdo con la Suprema Corte de Justicia de la Nación, el principio de igualdad es vinculante no sólo frente a los órganos del Estado, sino que igualmente poseen eficacia jurídica en ciertas relaciones entre particulares. ${ }^{10}$ Este criterio de la máximo Tribunal ha generado consecuencias en los ámbitos laboral y civil, por ejemplo.

Asimismo, el Poder Ejecutivo encuentra su límite en el principio de igualdad, mismo que supone tanto el reconocimiento como el cumplimiento efectivo de los derechos humanos, es decir se proyecta como una limitación a la arbitrariedad y discrecionalidad del Ejecutivo. Además de los limites al Ejecutivo, derivado del artículo 89 fracción X de la Constitución, se le impone como obligación el respeto, la protección y la promoción de los derechos humanos.

La Constitución Política de los Estados Unidos Mexicanos, contiene en los artículos $1^{\circ}$., $2^{\circ}$., $4^{\circ}$., $12^{\circ}$., y $13^{\circ}$., manifestaciones del principio de igualdad de manera expresa. La prohibición de discriminar contenida en el artículo $1^{\circ}$ constitucional, obliga a respetarla a todos sin excepción alguna, por lo tanto, está dirigida a los órganos del Estado y a los particulares; el Estado tiene además el deber de proteger y promover el derecho que toda persona tiene a no ser discriminada.

Se reconoce en el artículo $4^{\circ}$ constitucional la composición pluricultural del país. A partir de tal reconocimiento, la pertenencia a un pueblo indígena determina la asignación de una

\footnotetext{
9 Tesis: $1^{a}$. CCCLXXXV/14, Semanario Judicial de la Federación, Décima Época, t. 1, noviembre de 2014 , p. 719.

10 Tesis: $1^{\mathrm{a}}$. XX/13, Semanario Judicial de la Federación, Décima Época, t. 1, enero de 2013, p.627 
determinada posición social dentro de una comunidad, esto es, ser niño o indígena. Del mismo texto constitucional se desprende que esta posición debe ser considerada en todos los juicios y procedimientos que involucren a indígenas, para juzgar si cierto tratamiento jurídico diferenciado constituye o no una violación al principio de igualdad. Por otra parte, el legislador tiene la obligación de aplicar en las nuevas leyes aquellos criterios de carácter genérico definidos en el artículo $1^{\circ}$ constitucional y, además, debe realizar una revisión exhaustiva de los ordenamientos vigentes y, en su caso, efectuar las reformas pertinentes tendentes a su armonización con los criterios constitucionales.

$\mathrm{El}$ artículo $4^{\circ}$ reconoce la igualdad entre mujeres y hombres, misma que se reconoce en diferentes ámbitos de derechos y responsabilidades. La importancia del reconocimiento de la igualdad entre la mujer y el varón hizo imprescindible la expedición de leyes secundarias para hacer operativo ese derecho.

La igualdad contenida en el artículo $12^{\circ}$ constitucional, se manifiesta como la prohibición de distinciones derivadas de títulos nobiliarios, honores o prerrogativas hereditarias, supone, de acuerdo con el artículo $1^{\circ}$, la prohibición de todo tipo de discriminación, lo que cierra la puerta a toda forma de estamentalismo y reafirma la igualdad desde el nacimiento de la persona.

El artículo $13^{\circ}$ constitucional contiene de manera concreta, el principio de igualdad. Derivado de este principio, el citado artículo constitucional expresa una serie de prohibiciones y limitaciones que se traducen en la igualdad ante la ley, manifestación del principio de igualdad al que más adelante se hará referencia.

\section{LA IGUALDAD FORMAL}

De acuerdo con Soberanes Díez, la igualdad como principio comprende dos dimensiones, una formal y otra material.1

Explica Pérez Luño que la igualdad formal suele identificarse con la exigencia jurídicopolítica sintetizada en el principio de igualdad ante la ley, principio que supone el reconocimiento de un mismo estatuto jurídico para todos los ciudadanos, lo que implica la garantía de la paridad de trato en la legislación y en la aplicación del derecho. ${ }^{12}$ De lo expresado por Pérez Luño se concluye que las manifestaciones de la igualdad formal son: la igualdad ante la ley, la igualdad en la ley y la igualdad en la aplicación de la ley.

Por otra parte, Cerdá Martínez-Pujalte afirma que las manifestaciones de la igualdad formal son la igualdad ante la ley, la igualdad en la aplicación de la ley, la igualdad en el contenido de la ley y el mandato de no discriminación. ${ }^{13}$

Se toman en cuenta los dos enfoques antes expuestos, como guía para emprender el análisis de cada una de las dimensiones de la igualdad formal a que aluden los autores citados.

Si se analiza a la igualdad como derecho, puede afirmarse que la igualdad es el derecho que inherente a todos los seres humanos a ser iguales en su dignidad, a ser tratados con respeto y consideración; derecho que debe poder ejercerse libremente por todas las personas y así, participar de manera igualitaria con todos los demás en cualquier ámbito de la vida social, político, civil, económico y cultural. La igualdad formal implica un trato igual, que se compendia en la igualdad ante la ley.

\footnotetext{
${ }^{11}$ SOBERANES DÍEZ, José María, La igualdad y la desigualdad jurídicas, Op. Cit., nota 8, pp. 35-36.

12 PÉREZ LUÑO, Antonio Enrique, Dimensiones de la igualdad, 2a ed., Madrid, Dykinson, 2007, p.19.

${ }^{13}$ CERDÁ MARTÍNEZ-PUJALTE, Carmen María, Op. Cit., nota 3, p. 194.
} 


\section{LA IGUALDAD ANTE LA LEY Y SUS MANIFESTACIONES}

Uno de los postulados básicos del constitucionalismo ha sido la igualdad ante la ley. En un primer momento, se trataba de reconocer la igualdad de todos los ciudadanos ante los derechos y deberes previstos en el ordenamiento jurídico, es decir, la igualdad de trato de todas las personas. ${ }^{14}$

El reconocimiento de la igualdad en el Estado liberal de Derecho, pretendía aclarar que después de un período de abuso en el ejercicio del poder, desaparecían los privilegios y la ley sería idéntica para todos, sin distinciones de ningún tipo. ${ }^{15}$ La ley como fuente suprema debía ser aplicada a todos por igual sin valorarse en términos de justicia material. Con la democratización de los regímenes liberales, la ley deja de ser fuente suprema y ahora, es la Constitución, como norma fundamental del Estado, la que va a marcar los límites al legislador impulsando su carácter social. ${ }^{16}$ Ese carácter social obliga a entender la ley desde otra concepción. La ley no debe ser igual para todos si lo que se busca es la obtención de la igualdad real.

La igualdad ante la ley se presenta como la exigencia de que todos los ciudadanos se someten igualmente al ordenamiento jurídico, y que todos tengan igual derecho a invocar la protección de los derechos que el ordenamiento reconoce, sin que ningún tipo o estamento de personas queden dispensadas de su cumplimiento, o sujetos a una legislación o jurisdicción diferente. ${ }^{17}$

En este sentido se identifica con la necesidad de generalidad e impersonalidad con la que han de ser tipificados los supuestos de hecho a los que la norma les atribuye consecuencias jurídicas. Lo cual, excluye, como regla, la aceptación de inmunidades, privilegios o la predeterminación en la disciplina de las situaciones jurídicas.

La igualdad formal debe completarse con la igualdad material, dando paso a la igualdad ante la ley como exigencia de equiparación, que según Pérez Luño, supone un trato igual de circunstancias o de situaciones no coincidentes. ${ }^{18}$ El autor afirma que se trata de llevar a cabo juicios de equiparación que consisten en establecer el criterio de relevancia a partir del cual se van a estimar los datos como esenciales o irrelevantes para manifestar la igualdad entre una pluralidad de objetos, situaciones o personas.

De acuerdo a este autor, el objetivo del criterio de relevancia consiste en no equiparar arbitrariamente aquellas cosas entre las que se dan diferencias relevantes o, no establecer discriminaciones entre aquellas personas $\mathrm{u}$ objetos cuyas divergencias deban considerarse irrelevantes. La noción de igualdad ante la ley no se agota en el imperativo de generalidad, esta es solo una de las exigencias de la igualdad ante la ley. La equiparación, diferenciación y regularidad completan las manifestaciones de la igualdad ante la ley.

En definitiva, el principio de igualdad ante la ley (o, dicho en términos negativos, el de no discriminación), no supone que todos deban ser tratados en cualquier circunstancia del mismo modo, sino que hay ciertas características que en principio no pueden utilizarse para

\footnotetext{
${ }^{14}$ CORCHETE MARTÍN, María José, “Algunos apuntes sobre la igualdad en la constitución española y su situación sobre la mujer”, en González Bustos, María de los Angeles (coord.), La mujer ante el ordenamiento jurídico: Soluciones a realidades de género, Barcelona, Atelier, 2009, p.58.

${ }^{15}$ PÉREZ LUÑO, Antonio Enrique, Dimensiones de la igualdad, Op. Cit., nota 12, pp. 22-24.

${ }^{16}$ CORCHETE MARTÍN, María José, "Algunos apuntes sobre la igualdad en la constitución española y su situación sobre la mujer”, Op. cit., p. 58.

${ }^{17}$ CERDÁ MARTÍNEZ-Pujalte, Carmen María, Op. Cit., nota 3, p. 202.

${ }^{18}$ PÉREZ LUÑO, Antonio Enrique, Op. Cit., nota 12, pp. 22-28.
} 
establecer diferencias de trato entre la gente. ${ }^{19}$ Esta igualdad implica que los órganos encargados de la aplicación del derecho no deben distinguir donde la ley no distingue. ${ }^{20}$

Así, la igualdad de todos ante la ley manifiesta su carácter formal, no obstante el conocimiento de la existencia de diferencias específicas, se pondera el postulado constitucional de dar un trato igual a los desiguales. Es decir, todas las personas son iguales ante la ley, sin establecer distinciones de ninguna clase; las mismas leyes rigen para todas las personas y, a todas le son aplicables sin excepción.

La generalidad de la ley propicia que exista la igualdad ante la ley, no obstante, la igualdad ha de manifestarse en la igual aplicación de la ley.

a) La igualdad en la aplicación de la ley

La igualdad en la aplicación de la ley, es un mandato dirigido al juzgador y exige igualdad de trato en todos los casos en que exista coincidencia en sus cualidades relevantes. La igualdad de trato tiene relación con una decisión uniforme, es decir, que siendo los casos iguales en cuanto a las cualidades relevantes, la decisión no puede variar. No obstante, puede darse la circunstancia de que dos casos sean iguales y reciban tratos desiguales en base a ciertas diferencias que justifican la desigualdad de trato.

La igualdad en la aplicación de la ley, implica la aplicación de la misma norma general en los diferentes casos sin excepción. Así se garantiza la imparcialidad, con lo que se asegura que la ley será aplicada sólo a los casos que son iguales en sus propiedades relevantes. La igualdad en la aplicación de la ley parte de la prohibición de la arbitrariedad. Para determinar si ha habido o no arbitrariedad en la aplicación de la norma será necesario que el órgano jurisdiccional encargado de analizar ese caso examine con criterios objetivos la oportunidad de la medida o decisión adoptada. ${ }^{21}$ Es decir, para determinar si un caso ha de ser considerado igual a otro, será necesario establecer algún criterio de relevancia que permita decretar esa igualdad.

Según Rubio Llorente, la igualdad en la aplicación de la ley encierra un mandato dirigido a los poderes públicos, encargados de aplicar el derecho, a través del cual se les obliga a no interpretar y aplicar la norma de manera distinta en situaciones que sean sustancialmente iguales y a establecer una adecuada proporcionalidad entre las diferencias que la norma reconoce. ${ }^{22}$ En el caso de México, la jurisprudencia obliga a los jueces de tribunales jerárquicamente inferiores, a tomar en cuenta las razones consideradas en decisiones anteriores cuando se trata de resolver casos que sean sustancialmente iguales o parecidos.

La igualdad en la aplicación de la ley encierra la prohibición de diferencia de trato sin una justificación y que, por lo tanto resultan arbitrarias. El juzgador puede modificar un criterio, siempre que pueda aportar las razones suficientes para tal cambio.

\footnotetext{
${ }^{19}$ FERNÁNDEZ RUíZ-GÁLVEZ, María Encarnación, Igualdad y derechos humanos, Madrid, Tecnos, 2003, pp. 57 ss.

${ }^{20}$ GIMÉNEZ GLUCK, David, et al., Una manifestación polémica del principio de igualdad: Acciones positivas moderadas y medidas de discriminación inversa, Valencia, Tirant lo Blanch, 1999, pp. 23-24.

${ }^{21}$ MOSQUERA, Susana, "Derecho a la igualdad y medidas de garantía en el proyecto de ley orgánica de igualdad", Anuario de la Facultade de Dereito da Universidade da Coruña, España, núm. 10, 2006, p. 777. http:// hdl.handle.net/2183/2424 (consultado el 2 de agosto de 2013)

${ }^{22}$ RUBIO LLORENTE, Francisco, "La igualdad en la aplicación de la ley", en García San Miguel, Luis (ed.), El principio de igualdad, España, Dykinson, 200o, pp. 47-49. http://dialnet.unirioja.es/servlet/libro?codigo=887 (consultado el 24 de agosto de 2013)
} 


\section{B) IGUALDAD EN EL CONTENIDO DE LA LEY}

El principio de igualdad garantiza a todas las personas igualdad ante la ley y en el contenido de la ley como destinatarios de las normas.

El principio de igualdad contiene la exigencia de tratar igual a los iguales y desigual a los desiguales, por lo tanto, en determinadas situaciones se prohíbe hacer cualquier distinción, no obstante, en otras circunstancias se permiten ciertas diferenciaciones siempre que estas sean justificadas. La concepción de la igualdad en el contenido de la ley, se enfoca a su contenido constituyendo un límite a la discrecionalidad del legislador, así el legislador no es más la medida de la igualdad, sino que está sometido al principio de la igualdad, a no establecer discriminación o diferenciación sin justificación racional y razonable. ${ }^{23}$

En aquellos casos en que la ley distingue entre dos o varios hechos o personas, corresponderá al máximo tribunal analizar si esa distinción se sustenta sobre una base objetiva y razonable o bien, si se trata de una discriminación prohibida por la Constitución. Para llegar a una conclusión será necesario determinar si la distinción legislativa tiene una finalidad objetiva y válida desde el punto de vista de la Constitución, dado que el legislador no puede insertar tratos desiguales arbitrariamente, sino que debe hacerlo dentro de los términos previstos por la Constitución.

Asimismo, será preciso examinar la racionalidad de la distinción que el legislador realizó, con la finalidad de precisar la existencia de una relación de tipo instrumental entre la medida categorizada y el fin que se quiere lograr.

Aunado a lo anterior, tendrá que cumplirse la exigencia de la proporcionalidad, pues el legislador no puede tratar de alcanzar objetivos constitucionalmente legítimos de manera manifiestamente desproporcional, por lo tanto, el juzgador debe determinar si la distinción legislativa se encuentra dentro del catálogo de tratamientos considerados como proporcionales, tomando en cuenta la situación de hecho, la finalidad de la ley y los bienes y derechos constitucionales afectados por tal distinción, dado que el logro de un propósito constitucional no puede hacerse a expensas de una afectación innecesaria o desmedida de otros bienes y derechos constitucionalmente protegidos.

Por otra parte, es imprescindible que en cada caso se determine respecto de qué se está exhortando con la igualdad, en razón de que cuando se realiza el control de constitucionalidad de las leyes, ese referente es relevante, para determinar el ámbito en donde el legislador tiene mayor espacio para realizar su actividad. De acuerdo a lo anterior, es oportuno hacer referencia a la afirmación de Pérez Portilla, en el sentido de que la imposición de llevar la igualdad al contenido de la ley, dirigida al legislador, se realiza recogiendo el principio de igualdad en las Constituciones y estableciendo un control de constitucionalidad. ${ }^{24}$

El planteamiento de Soberanes Díez, reafirma lo que antes se expuso, en el sentido de que el juicio de razonabilidad tiene dos componentes: racionalidad y proporcionalidad. Así, el juicio de racionalidad implica la comparación entre dos situaciones jurídicas. ${ }^{25}$ Para este autor, la primera situación jurídica se deriva de la norma impugnada y recibe el nombre

\footnotetext{
${ }^{23}$ NOGUEIRA ALCALÁ, Humberto, "El derecho a la igualdad ante la ley, la no discriminación y acciones positivas", Anuario da Facultade de Dereito da Universidade da Coruña, España, núm. 10, 2006, pp. 806-810. http://hdl.handle.net/2183/2449 (consultado el 26 de agosto de 2013)

${ }^{24}$ PÉREZ PORTILLA, Karla, Principio de igualdad: Alcances y perspectivas, México, UNAM- Consejo Nacional para Prevenir la Discriminación, 2005, p.87.

${ }^{25}$ SOBERANES DÍEZ, José María, Op. Cit., nota 8, pp. 137-138.
} 
de razón o término impugnado; la segunda situación sirve para predicar la igualdad o desigualdad respecto a la primera y es conocida como término de comparación. En el caso de la igualdad, el juicio de proporcionalidad, debe aplicarse para determinar si el trato desigual es proporcional, utilizando los mismos parámetros de adecuación, necesidad y proporcionalidad en stricto sensu. ${ }^{26}$

c) La prohibición de discriminar.

La discriminación es una práctica de exclusión que vulnera la dignidad, los derechos humanos y las libertades fundamentales de las personas. Se puede discriminar mediante un trato desigual o a través de un trato igual. Pérez Portilla afirma que discriminar es practicar un tratamiento desigual que no resulta admisible; es decir, la discriminación no se equipara a cualquier trato desigual sino a una desigualdad que toma como base un criterio no razonable e incluso prejuicioso y estigmatizador. Por lo tanto, el contenido del mandato de no discriminación se formularía de la siguiente manera: a menos que exista una razón reconocida como relevante y suficiente, según algún criterio identificable y aceptado, ninguna persona debe ser preferida a otra. ${ }^{27}$

La prohibición de discriminar es de carácter general, por lo tanto todos tenemos el deber de respetarla. La generalidad de la prohibición de discriminar permite que la obligación de actatarla se destine a todos los órganos Estado y a particulares. La prohibición de discriminar impone un límite a la actividad estatal y compromete al Poder Ejecutivo, al Poder Legislativo y al Poder Judicial en sus respectivos ámbitos de competencia, a cumplir con el deber de respetar las disposiciones constitucionales.

Para el Poder Ejecutivo, la prohibición de discriminar reside en cuidar que todas sus acciones estén exentas de todo tipo de trato discriminatorio, además del imprescindible deber de respetar la igualdad ante la ley, por tanto, está impedido de hacer cualquier distinción que resulte contraria a la dignidad de las personas. Para el Poder Legislativo, esta prohibición se traduce en un mandato que consiste en velar que las leyes no contengan categorizaciones que establezcan diferencias entre personas limitando los derechos de algunas de ellas.

La impartición de justicia a cargo del Poder Judicial, lo obliga a vigilar que las partes en los juicios disfruten de igualdad ante la ley; realizar el control de constitucionalidad de las leyes para que en éstas, no se establezcan diferencias arbitrarias e injustificadas y, se cumpla la prohibición de discriminar, a través de la actividad jurisdiccional.

Por otra parte, Cerdá Martínez-Pujalte afirma que la prohibición de discriminación permite rechazar tratamientos desiguales como las diferenciaciones por razón de sexo, raza o ideología; diferencias que no deben tomarse en cuenta a la hora de aplicar el principio de igualdad de trato. Así, la prohibición de discriminación opera estableciendo cuándo no está justificado un tratamiento normativo diferente en virtud de esas diferenciaciones. ${ }^{28}$

Laporta explica que igualdad es, de modo inmediato, no discriminación, y no discriminación es simplemente la cancelación de diferencias como razones relevantes para la diferenciación normativa. Afirma que no debe haber diferencias normativas que tomen como base rasgos irrelevantes. ${ }^{29}$

Según Laporta, el núcleo de la prohibición de discriminación es:

\footnotetext{
${ }^{26}$ Ibídem, pp. 151-152.

27 PÉREZ PORTILLA, Karla, Op. Cit., nota 24, p. 109.

${ }^{28}$ CERDÁ MARTÍNEZ-PUJALTE, Carmen María, Op. Cit, nota 3, p. 196.

${ }^{29}$ LAPORTA, Francisco J., "El principio de igualdad: Introducción a su análisis”, Sistema, Madrid, núm. 67, 1985, p. 10. http://dialnet.unirioja.es/servlet/articulo?codigo=32756 (consultado el 8 de abril de 2013).
} 
El señalar con nitidez la relevancia e irrelevancia de los rasgos, pues precisamente porque prescribe que frente a rasgos irrelevantes no debe haber diferenciación en la consecuencia normativa, necesariamente determina también que cuando en las condiciones de aplicación de la norma aparezca un rasgo relevante diferenciador, mantener el tratamiento normativo igual, es decir, no diferenciar, sería incorrecto. ${ }^{30}$

Como ya se dijo, el principio de igualdad ante la ley es un mandato dirigido al legislador que ordena el trato igual a todas las personas. La discriminación contra una persona o grupo tiende a una diferenciación injusta generada por diversos factores, que tienen el efecto de excluirlos del goce o el ejercicio de sus derechos.

El mandato de no discriminación, además de evitar diferencias de trato susceptibles de ser rechazadas por su afectación a la dignidad humana, trata de proteger a grupos desfavorecidos y discriminados, para procurarles una igualdad efectiva. ${ }^{31}$

Todas las personas pueden ser objeto de discriminación, sin embargo, cuando se trata de grupos vulnerables o en situación de desventaja, la discriminación proviene del trato igual que se les da en la ley.

El reconocimiento de igualdad de todas las personas ante la ley, no implica que deba darse un trato igualitario a todos los grupos de personas. Por el contrario, se debe procurar que, en iguales condiciones, se apliquen las mismas medidas jurídicas. Existen grupos de personas que, por sus condiciones particulares, se encuentran en una situación distinta a los demás, de manera que, de otorgárseles el mismo trato, se les estaría colocando en una condición de desventaja que resultaría discriminatoria. En ese sentido, a las personas que se encuentran, objetivamente, en una situación distinta a la de las demás, y se otorga un trato igualitario en ambos casos, implicaría una vulneración al mandato de no discriminar.

Cuando la desigualdad de trato se basa en algún rasgo característico de las personas pertenecientes a un grupo social o en una característica indisociable con éste, la discriminación es directa. En tanto que la discriminación es indirecta cuando se aplica un criterio o disposición que es aparentemente neutro, pero que provoca efectos desproporcionalmente perjudiciales para algún grupo social. ${ }^{32}$

La discriminación indirecta existe, con independencia de que haya o no intención de discriminar, por los resultados o consecuencias que se derivan de cierta acción, con excepción de los casos en los que esté justificada por factores objetivos.

Examinadas las manifestaciones de la igualdad formal, puede afirmarse, siguiendo a Pérez Portilla, que cuando un ordenamiento jurídico reúne al mandato de no discriminación señalado de manera expresa y al principio genérico de igualdad que incluye la igualdad ante la ley, la igualdad en la aplicación de la ley y la igualdad en el contenido de la ley; garantiza

\footnotetext{
${ }^{30}$ Ibidem, p. 15.

${ }^{31}$ Comisión Nacional de los Derechos Humanos, La discriminación y el derecho a la no discriminación, México, CMDH, 2012, pp. 9-10.

${ }^{32}$ PÉREZ PORTILLA, Karla, Op. Cit., nota 24, pp. 109-118.
} 
la doble función que le corresponde a la igualdad: ser límite objetivo del poder y ser derecho fundamental de la persona.

Sin embargo, la prohibición de discriminar no se restringe a las acciones de los poderes públicos, sino que se dirige igualmente a los particulares, si no fuera así la supremacía constitucional estaría subordinada a las acciones de los particulares.

Para los particulares, el deber de abstenerse de cualquier acto que vulnere la Constitución, conlleva la obligación de respetar los derechos de no discriminación y de igualdad real de oportunidades. La prohibición de discriminar puede aplicarse a las relaciones entre particulares, por ejemplo, los empleadores no podrán lícitamente distinguir entre sus trabajadores con base en alguno de los criterios prohibidos en la Constitución. Podrá aducirse que la prohibición de discriminar limita la autonomía de la voluntad, sin embargo, la dignidad de la persona debe ponerse por encima de la libertad contractual. Es oportuno señalar que para corregir las situaciones discriminatorias puede recurrirse a las acciones positivas o afirmativas.

\section{LA IGUALDAD SUSTANTIVA O MATERIAL Y SUS MANIFESTACIONES}

La igualdad sustantiva es la igualdad material o de hecho por oposición a la igualdad formal. La igualdad sustantiva supone la modificación de las circunstancias que impiden a las personas el ejercicio pleno de los derechos y el acceso a las oportunidades a través de medidas estructurales, legales o de política pública. ${ }^{33}$

Se considera que la igualdad material es el estadio más reciente en el recorrido de la igualdad a través del texto de las Constituciones más modernas, ${ }^{34}$ para las que, ya no es suficiente con garantizar la igualdad formal en las leyes. El principio de igualdad material requiere del Estado la obligación de actuar en la sociedad para lograr la igualdad real de los ciudadanos; ${ }^{35}$ o en palabras de Carbonell, el compromiso del Estado de remover los obstáculos que en el plano económico y social configuran efectivas desigualdades de hecho que se oponen al disfrute efectivo del derecho. ${ }^{36}$

La igualdad sustantiva o material admite que el Estado como garante de los derechos tiene, además del deber general de no discriminar, la obligación de adoptar acciones afirmativas o positivas como estrategia para acelerar la participación en condiciones de igualdad de todas las personas en todos los ámbitos. Las acciones afirmativas o positivas deben aplicarse no como excepción a la regla de no discriminación, sino como estrategia indispensable para lograr la igualdad sustantiva en el goce y ejercicio de sus derechos.

En los siguientes apartados, se hace referencia a las manifestaciones de la igualdad sustancial.

\footnotetext{
${ }^{33}$ Instituto Nacional de las Mujeres, Compendio normativo para la construcción de igualdad sustantiva en la Administración Pública Federal, México, INMUJERES, 2013, p. 3.

34 PÉREZ PORTILLA, Karla, “Acciones positivas”, en Carbonell, Miguel (coord), Anuario 2003 de la Enciclopedia Jurídica Mexicana, México, Porrúa-UNAM, 2003, pp. 2-5.

35 PÉREZ PORTILlA, Karla, Op. Cit., nota 24, p. 136.

${ }^{36}$ CARBONELL, Miguel, Igualdad y libertad. Propuestas de renovación constitucional, México, UNAM-CNDH, 2007, pp. 85-86.
} 


\section{A) LA IGUALDAD DE OPORTUNIDADES}

Desde la Constitución se impone a todas las autoridades, en el ámbito de sus respectivas competencias, la obligación de promover, respetar, proteger y garantizar los derechos humanos de todas las personas, entre ellos el de la igualdad de oportunidades.

Por medio de la igualdad de oportunidades se pretende generar condiciones sociales, jurídicas, política y económicas para aquellos que se encuentran en situación de desventaja, de manera que, a través de esas condiciones dispongan de las mismas oportunidades que los que se encuentran en una situación diferente.

Así, la igualdad de oportunidades supone que dadas las condiciones, los problemas originados por la discriminación institucional desaparecen, entonces las personas deberían ser tratadas con igualdad prescindiendo de toda característica asignada. Sin embargo, la igualdad de oportunidades no asegura resultados. No es suficiente garantizar un punto de partida idéntico, dado que la igualdad de oportunidades no puede entenderse sin la responsabilidad individual.

Siguiendo a Fernández Ruíz-Gálvez, puede decirse que la igualdad de oportunidades, aunque necesaria, resulta insuficiente por sí solo para producir una distribución justa del poder y de los ingresos y riquezas. De ahí la necesidad de complementarla con una cierta igualdad de resultados, entendiendo por tal la satisfacción de las necesidades básicas de todas las personas, unida a la reducción de las desigualdades sociales y económicas excesivas. ${ }^{37}$

Para el logro de la de la igualdad de oportunidades se necesita garantizar que no existe ningún tipo de discriminación; que en la distribución de los recursos exista igualdad y la exigencia de acciones positivas.

\section{B) LA IGUALDAD EN LOS RESULTADOS.}

La igualdad en los resultados o igualdad en el punto de llegada es vista como la culminación lógica de la igualdad sustantiva. Alarcón Cabrera afirma que la igualdad de resultados es un instrumento corrector de los impedimentos que frenan la auténtica realización de la igualdad de oportunidades. ${ }^{38}$

La igualdad de oportunidades debe depender del Estado y los resultados de las personas. Es obligación del Estado brindar igualdad de oportunidades para todos, para una justa nivelación de situaciones desde el mismo punto de partida. La igualdad de resultados es obligación de la persona, los resultados dependerán del compromiso y del esfuerzo individual.

La igualdad de resultados no pretende que los resultados sean entendidos como productos finales idénticos u homogéneos, derivados del ejercicio de los derechos, sea que se les considere como resultados individuales o de grupo. La igualdad de resultados se refiere a que todas y todos por igual tienen asegurado y garantizado el ejercicio del derecho de que se trate. La igualdad persigue como resultado que las personas puedan gozar y ejercer sus derechos, para lo cual es necesario eliminar cualquier distinción, exclusión o restricción basada

37 FERNÁNDEZ RUÍZ-GÁLVEZ, María Encarnación, "Igualdad, diferencia y desigualdad. A propósito de la crítica neoliberal de la igualdad", España, núm. 10, 1993, p. 63. http://dialnet.unirioja.es/servlet/ articulo?codigo $=142261$,_(consultado el 8 de septiembre de 2013)

${ }^{38}$ ALARCÓN CABRERA, Carlos, "Reflexiones sobre la igualdad material", Anuario de Filosofía del Derecho, Madrid, número 4, 1987 p. 34. http://dialnet.unirioja.es/servlet/ejemplar?codigo=14277 (consultado el 10 de octubre de 2013) 
en el sexo que puedan anular el goce y ejercicio de esos derechos, mismos que, en opinión de García Prince, el resultado igualitario está en la posibilidad del goce y ejercicio de los derechos y no en los productos o circunstancias personales específicos de los actos individuales. ${ }^{39}$

La igualdad implica derechos individuales y derechos colectivos; desde esta dimensión se plantea la igualdad de oportunidades, de trato y de resultados. El único resultado uniforme que busca la igualdad de resultados es que todas y todos puedan ejercer sus derechos sin discriminaciones y con oportunidades y trato que favorezca tal ejercicio, lo que hace ostensible el vínculo e interdependencia existente entre estos tres conceptos: igualdad de oportunidades, igualdad de trato e igualdad de resultados. ${ }^{40}$

Para Prieto Sanchís, el punto central de la igualdad consiste en determinar cuáles son los rasgos que representan una razón para un tratamiento igual o desigual, ${ }^{41}$ rasgos que deben ser tanto el criterio de la condición de aplicación como el fundamento de la consecuencia jurídica.

\section{CONCLUSIONES}

La igualdad en el sistema jurídico mexicano ha avanzado significativamente, a partir de su pleno reconocimiento desde la Constitución, convirtiéndose así en uno de los principios que sustentan los derechos humanos.

La importancia del reconocimiento en el texto constitucional de la igualdad como principio radica en que servirá de fundamento tanto para la producción normativa como para las reformas de las leyes ya existentes que regulan aspectos específicos de la igualdad.

La percepción del principio de igualdad como norma se refiere a la igualdad respecto de las leyes destinadas a regular los derechos de las personas por igual, con independencia de sus particularidades, constituyéndose así en una garantía del orden jurídico.

La expresión más importante del principio de igualdad está contenida en el párrafo tercero del artículo primero de la Constitución en el que este principio se concreta como una prohibición de discriminar. Es decir, se establecen aquellos criterios que no pueden ser tomados en cuenta para originar una diferencia o distinción. El principio de igualdad contenido en este precepto supone la eliminación de todo trato desigual, a menos de que exista una razón para hacerlo. Por lo que debe entenderse como una exigencia de tratar igual a los iguales y desigual a los desiguales, por lo tanto, hacer distinciones se prohíbe en unos casos mientras que en otros se permite.

Puede considerarse que el principio de igualdad posee un carácter absoluto en el sentido de que, en principio, todas las personas, son sujetos frente al derecho y por tanto reciben igual protección del orden normativo principio, deben guardar la misma posición frente al orden jurídico, es decir toda persona es igual ante la ley. Este principio, puede ser visto como

\footnotetext{
39 GARCÍA PRINCE, Evangelina, Políticas de igualdad, equidad y gender mainstreaming ¿De qué estamos hablando? Marco conceptual, San Salvador, Programa de las Naciones Unidas, 2008, p. 38. http://webs.uvigo. es/pmayobre/descargar_libros/evangelina_garcia_price/politicas.pdf (consultado el 16 de octubre de 2013)

${ }^{40}$ Ibidem, p. 39.

${ }^{41}$ PRIETO SANCHÍS, Luis, “Igualdad y minorías”, en Prieto Sanchís, Luis (coord.), Tolerancia y minorías: Problemas jurídicos y políticos de las minorías en Europa, España, Universidad de Castilla-La Mancha, 1996, p. 31.
} 
un principio relativo al considerar que las personas deben recibir el mismo trato en situaciones similares, es decir, obedece a un cierto estado de cosas.

Sobre el principio de igualdad ante la ley y en la aplicación de la ley, descansa toda la estructura del orden jurídico nacional e internacional; se trata de normas que no admiten ni la exclusión ni la alteración de su contenido y que como principio fundamental se proyecta hacia todo el ordenamiento jurídico, sin que exista posibilidad de que este principio colisione con algún acto jurídico.

Para la protección de los derechos humanos, el principio de igualdad y no discriminación es fundamental tanto en el ámbito nacional como internacional. A través de esta manifestación de la igualdad se deja en claro la obligación a cargo de los Estados de eliminar de sus ordenamientos jurídicos toda norma de contenido discriminatorio. El principio de igualdad y no discriminación procura asegurar que todas las personas gocen y ejerzan sus derechos humanos en los hechos y en igualdad de circunstancias.

De esta manera, se transciende el concepto de igualdad meramente formal para llegar a una igualdad sustancial o material que, en términos generales se refiere a la remoción de aquellos obstáculos que en el ámbito económico y social conforman desigualdades de hecho que se oponen al disfrute efectivo del derecho.

La igualdad sustancial se manifiesta en la igualdad de oportunidades y la igualdad de resultados. La primera se relaciona con las medidas antidiscriminatorias, al considerar que las personas no cuentan con las mismas oportunidades, por lo que se hace necesario adoptar medidas tendentes a reducir las brechas de desigualdad.

La igualdad de resultados es la culminación lógica de la igualdad sustantiva. Estos resultados pueden manifestarse en que, en diferentes campos, las personas disfruten de derechos en proporciones casi iguales, disfruten de niveles de salario iguales por trabajo igual o de igual valor y en que exista igualdad en la adopción de decisiones y en la influencia política, entre otras.

Así, el principio de igualdad se desenvuelve desde lo puramente abstracto y formal, que considera a todos los seres humanos como esencialmente iguales, hasta encontrar una igualdad que se manifieste en la realidad.

La igualdad emana de la naturaleza humana y se considera como inseparable de la dignidad de la persona y por lo tanto incompatible con cualquier situación de propicie un tratamiento que favorezca a un determinado grupo por considerarlo superior o bien, lo discrimine excluyéndolo de sus derechos por considerarlo inferior. Las diferencias de trato entre personas que no correspondan a su igual naturaleza no son admisibles. No obstante, como no toda distinción de trato puede considerarse ofensiva para la dignidad humana, no todo tratamiento diferente puede ser considerado como discriminatorio.

Puesto que los seres humanos no somos iguales; somos diferentes, la diferencia y la desigualdad son la causa que conduce a reflexionar que la igualdad es la relación que las personas guardan con el goce y ejercicio de sus derechos. 
FUENTES

BIBLIOGRÁFICAS

ALARCÓN CABRERA, Carlos, "Reflexiones sobre la igualdad material", Anuario de Filosofía del Derecho, Madrid, número 4, 1987. http://dialnet.unirioja.es/servlet/ ejemplar? codigo $=14277$ (consultado el 10 de octubre de 2013)

ALEXY, Robert, Teoría de los derechos fundamentales, Madrid, Centro de Estudios Constitucionales, 1993. http://www.iedf.org.mx/sites/DDHH/publicaciones/o1.pdf

CARBONELL, Miguel, Igualdad y libertad. Propuestas de renovación constitucional, México, UNAM-CNDH, 2007.

Miguel, Igualdad y constitución, México, Consejo Nacional para Prevenir la Discrimiación, 2004.

CASTRO, Juventino V., Garantías y Amparo, 14ª ed., México, Porrúa, 2004.

CERDÁ MARTÍNEZ-PUJALTE, Carmen, "Los principios constitucionales de igualdad de trato y de prohibición de la discriminación: Un intento de delimitación”, Cuadernos constitucionales de la Cátedra Fadrique Furió Ceriol, España, núm. 50-51, 2005. http://dialnet.unirioja.es/servlet/articulo? codigo=2538666 (consultado el 11 de julio de 2014)

Comisión Nacional de los Derechos Humanos, La discriminación y el derecho a la no discriminación, México, CMDH, 2012.

CORCHETE MARTÍN, María José, “Algunos apuntes sobre la igualdad en la constitución española y su situación sobre la mujer”, en González Bustos, María de los Ángeles (coord.), La mujer ante el ordenamiento jurídico: Soluciones a realidades de género, Barcelona, Atelier, 2009.

FERNÁNDEZ RUÍZ-GÁLVEZ, María Encarnación, "Igualdad, diferencia y desigualdad. A propósito de la crítica neoliberal de la igualdad", España, núm. 10, 1993. http:// dialnet.unirioja.es/servlet/articulo?codigo $=142261$ (consultado el 8 de septiembre de 2013)

, María Encarnación, Igualdad y derechos humanos, Madrid, Tecnos, 2003.

GARCÍA MORILLO, Joaquín, "La cláusula general de igualdad”, Derecho Constitucional, Valencia, Tirant lo Blanch, 2002, vol. I.

GARCÍA PRINCE, Evangelina, Políticas de igualdad, equidad y gender mainstreaming ¿De qué estamos hablando? Marco conceptual, San Salvador, Programa de las Naciones Unidas, 2008. http://webs.uvigo.es/pmayobre/descargar_libros/evangelina_garcia_ price/politicas.pdf (consultado el 16 de octubre de 2013)

GIMÉNEZ GLUCK, David, et al., Una manifestación polémica del principio de igualdad: Acciones positivas moderadas y medidas de discriminación inversa, Valencia, Tirant lo Blanch, 1999. 
Instituto Nacional de las Mujeres, Compendio normativo para la construcción de igualdad sustantiva en la Administración Pública Federal, México, INMUJERES, 2013.

LAPORTA, Francisco J., "El principio de igualdad: Introducción a su análisis", Sistema, Madrid, núm. 67, 1985. http://dialnet.unirioja.es/servlet/articulo?codigo=32756 (consultado el 8 de abril de 2013)

MOSQUERA, Susana, "Derecho a la igualdad y medidas de garantía en el proyecto de ley orgánica de igualdad", Anuario de la Facultade de Dereito da Universidade da Coru$\tilde{n} a$, España, núm. 10, 2006. http://hdl.handle.net/2183/2424 (consultado el 2 de agosto de 2013)

NOGUEIRA ALCALÁ, Humberto, "El derecho a la igualdad ante la ley, la no discriminación y acciones positivas", Anuario da Facultade de Dereito da Universidade da Coruña, España, núm. 10, 2006. http://hdl.handle.net/2183/2449 (consultado el 26 de agosto de 2013)

PÉREZ LUÑO, Antonio Enrique, "Dimensiones de la igualdad material”, Anuario de Derechos Humanos, España, núm. 3, 1984-1985.

Antonio Enrique, "El concepto de igualdad como fundamento de los derechos económicos, sociales y culturales”, Anuario de Derechos Humanos, España, núm 1, 1981.

Antonio Enrique, Dimensiones de la igualdad, $2^{\mathrm{a}}$ ed., Madrid, Dykinson, 2007.

PÉREZ PORTILLA, Karla, "Acciones positivas", en Carbonell, Miguel (coord), Anuario 2003 de la Enciclopedia Jurídica Mexicana, México, Porrúa-UNAM, 2003.

Karla, Principio de igualdad: Alcances y perspectivas, México, UNAMConsejo Nacional para Prevenir la Discriminación, 2005.

PRIETO SANCHÍS, Luis, "Igualdad y minorías", en Prieto Sanchís, Luis (coord.), Tolerancia y minorías: Problemas jurídicos y políticos de las minorías en Europa, España, Universidad de Castilla-La Mancha, 1996.

PRIETO SANCHÍS, Luis, Ley, principios, derechos, Madrid, Dykinson, 1998.

RODRÍGUEZ-PIÑERO, Miguel y FERNÁNDEZ LÓPEZ, Ma. Fernanda, Igualdad y discriminación, Madrid, Tecnos, 1986.

RUBIO LLORENTE, Francisco, "La igualdad en la aplicación de la ley", en GARCÍA SAN MIGUEl, Luis (ed.), El principio de igualdad, España, Dykinson, 200o. http://dialnet. unirioja.es/servlet/libro?codigo=887 (consultado el 24 de agosto de 2013)

Semanario judicial de la Federación y su Gaceta. Décima Época. https://www.scjn.gob.mx/ libreria/paginas/semanarioauto.aspx

SOBERANES DÍEZ, José María, La igualdad y la desigualdad jurídicas, México, Porrúa, 2011. 